A CASE OF POISONING FROM ARSENICAL

BY W. EVERETT SMITH, M.D., BOSTON, MASS.

Авочт the middle of September, 1886, my patient, Mrs. S., changed her residence from the country to the city. She very soon discovered that some ferns in her parlors were withering, but not from neglect or improper care, since although ultimately dying, they revived for a brief season upon being removed to another part of the house. In the early part of November, she suffered from an attack of nausea and a dizziness so intense, especially when she attempted to stoop, that for several days she was obliged to keep the bed. These symptoms persisted in their intensity about a fortnight, and were followed by a sharp attack of facial neuralgia which lasted about a week.

In the latter part of December, the dizziness re-appeared, but in a far milder form than it had been the month before. At about the same time she began to complain of extreme lassitude and a loss of pleasure in pursuits that formerly gave enjoyment. 'The quiet of her own room was the one thing that she eagerly sought.

Although she suffered from a continual slight nausea, her appetite was unusually good; there was, as she expressed it, an almost constant "gnawing in the stomach." After the eating of food the nausea would increase, and she would complain of a feeling of heaviness and uneasiness throughout the bowels, especially in the umbilical region. Her increase of adipose tissue began to be distressing to her. Although she had always before drank very little water, she now was thirsty all the time. The menstrual functions continued to be regular so that the symptoms presented were considered to be indicative of over-work and lose of nervous energy rather than of any physiological disturbance. The patient herself was disposed to consider her symptoms malarial in their nature, although, contrary to her expectations, quinine gave her no relief. Occasionally, she would speak of her eyes smarting and watering if she tried to use them.

Suddenly, on March 16,1887, she was taken without any apparent cause with headache, extreme nausea, and uncontrollable vomiting. The usual antiemetic remedies, internal and external, dietary and medicinal, were tried in turn, but all without relief. On the contrary, they seemed rather to increase her distress. The only expedient that gave the slightest semblance of relief was the holding of pieces of ice in the mouth. The vomiting was almost incessant and was increased by assuming the recumbent position. The vomitus consisted at first of mucus, on the third day of free blood, and later of thick yellow bile. Tenderness in the epigastric and right hypochondriac regions speedily developed itself. The temperature and pulse remained nearly normal. The nasal discharge was uniformly bloody. The menstrual functions still remained normal so that the symptoms seemed to indicate clearly an acute exacerbation of the same trouble that had existed all winter in a mild and chronic form.

Although I could not absolutely exclude either a primary gastro-duodenal ulceration or some of the freaks of pregnancy, I remembered the withering of the ferns and began strongly to suspect some form of

1 Read before the Section for Clinical Medicine, Pathology, and Hygiene, of the Suffolk District Medical Society, October 10, 1887 . irritant poisoning to be the cause of sickness. I accordingly sent samples of all the wall-papers in the house (except, of course, plain "cartridge" papers which I knew to be practically free from suspicion), to Dr. Edward S. Wood for examination. Upon analysis, he pronounced only one paper arsenical, but found such an amount of arsenic therein, that he advised its immediate removal.

To settle decisively the question of poisoning, the urine also was examined for arsenic. Six ounces collected on March 23d, the eighth day of the incessant vomiting, yielded numerous crystals of arsenic after re-sublimation in the tube, while a quart of urine collected three days later yielded a very dark deposit upon the tube, but after re-sublimation, scarcely a trace of arsenic crystals. This seemed to indicate not only that there had been a very large amount of arsenic in the system of my patient, but also that a rapid elimination of the poison was taking place.

But the vomiting and prostration continued unabated. For twenty days the patient could retain absolutely nothing upon the stomach. Enemata, both of beef tea and of Murdock's Food were attempted, but could not be retained. Finally, brandy was substituted for them and with better results. The temperature had never risen above $100^{\circ}$, nor the pulse much above 96 . At midnight of the twentieth day the nausea and vomiting ceased as suddenly as it had begun. The following morning the patient expressed her first desire for food. We began with Horlick's Food, and although during the next week we changed at her request to Mellen's, Hard's, and to Wells \& Richardson's Lactated Food, we returned to Horlick's and found it the best suited to the case. The recovery was rapid and complete in less than a fortnight. There was only one relapse that could be traced directly to arsenic.

It had seemed at first improbable not only to myself, but to Drs. Wood and Whittier, whom I consulted in the case, that the wall-paper already found to contain arsenic could be the sole cause of all this arsenical poisoning. The paper was upon the walls of a small room on the entrance floor of the house where the patient had been very little, the parlors were on the floor above, and her chamber on the floor above the parlors. In hopes, therefore, of finding some other source of arsenic, dress goods and window draperies were analyzed, but with negative results, so far as finding arsenic were concerned. Chromium was, however, found in large amounts in one pattern of dark green dress goods. I had early seen to it that all cretonnes and turkey-red material were removed from the chamber, since they are well-known to be highly charged with arsenic.

The almost conclusive proof, however, that the sole cause of my patient's sickness existed in this room is as follows: 'The dangerous wall-paper was removed while the patient was convalescent. She insisted that she was not yet strong enough to venture from home and so remained in the house, confined strictly to her room, while the work went on. After the walls had been scraped and washed, and the room thoroughly cleaned preparatory to the laying of the new paper, she ventured to look in to the room but remained there scarcely ten minutes. She very soon had a return of nausea and vomiting, which lasted nearly twenty-four hours. I thereupon insisted that she go into the country and that in her absence the entire house be 
thoroughly cleaned and dusted. This was done, and since her return she has presented no further symptoms of arsenic poisoning.

Another member of the family was affected by the removal of the paper, his symptoms taking the form of a sharp diarrhoea. The other two members did not at any time present marked symptoms of arsenical poisoning, except a noticeably sallow complexion and a pretty constant feeling of lassitude all winter. They had, however, had more exercise in the open air than my patient.

I trust the record of this case may stimulate physicians to investigate more thoroughly than they otherwise might, cases that they hastily assume to be the results of malaria, nervous prostration or other indefinite or undetermined causes. Many of these cases I believe to be simply chronic poisoning from some material source near at hand. The profession has learned that wall-paper and some kitchen utensils are often arsenical, and it is slowly realizing that articles of clothing and of household decoration may likewise be injurious to health, although the subject has not yet received the attention that it deserves. It seems to me that it is our duty as physicians interested in public health and preventive medicine to make renewed and concerted efforts to secure such laws as shall make it a criminal offence for a manufacturer to allow any deadly poison to be in fabrics or materials that are used or that are sold upon the market.

\section{REPORT ON GENITO-URINARY SURGERY.}

BY ABNER POST, M.D.

LITHOLAPAXY IN BOYS.

Dr. KeEGAN, ${ }^{1}$ of Indore, Central India, has published a series of papers on the subject of "Litholapaxy in Male Children" during the last four years, and various other papers. ${ }^{2}$ and reports on the same subject have recently appeared. The writers agree upon the possibility and advisability of Bigelow's operation in very young children. Dr. Keegan would as soon think of performing lateral lithotomy on an old man with a small uncomplicated stone as on a boy whose urethra would admit the passage of suitable lithotrites and evacuating catheters. The reports referred to here represent a total of eighty-nine cases of boys between the ages of fifteen months and eleven years. One case only was fatal and that was a case of Dr. Keegan in which the calculus was formed about a stalk which had penetrated the bladder through the rectum. It was a case better suited to lithotomy, and would have been so treated had the history been more carefully considered on his admission to the hospital.

The calibre of the urethra in boys reaches a much larger size than has been attributed to it.

Dr. Raye operated on a boy of twenty-three months using a No. 9 (English) lithotrite and evacuator. It passed with perfect ease and without any incision of the meatus, which was of comparatively monster calibre. The infant recovered without trouble of any

1 Indian Medical Gazette, May, 1884, June and September, 1885, June, 1886.

Lancet, 1886, ii, 1068, 1122, 1168. Also reprint.

2 W. J. Walsham, F. R. C. S. Litholapaxy v. Supra-pubic Lithotomy in Male Children. British Medical Journal, October 15, 1887, p.

Surgeon Major Goldsmith. Indian Medical Gazette, May, 1887 Raye, D. O'C. Cases of Litholapaxy in Male Children. India
Medical Gazette, Calcutta, 1887, xxii, May, 129-132. sort. Dr. Raye's last case was a boy of eight and a half. The smallest instrument in his possession was a No. 8. It would not pass the meatus which was incised. The instrument then passed rather tightly as far as the bulb beyond which it could not be passed without more force than seemed advisable. A No. 7 would liave passed, but he had no such instrument. In Mr. Willett's case, quoted by Walsham, a lithotrite and catheter of No. 6 (English) calibre were used successfully upon an infant of fifteen months. Dr. Keegan has passed a No. 7 (English) catheter into the bladder of a boy only eleven months old. It may seem strange that a false estimate of the normal size of the urethra in male children should have existed until very recently, but it is really no more strange than that surgeons should have believed up to the discovery of Otis that the male urethra is much smaller than it really is.

Dr. Keegan states that while no hard and fast rule can be laid down, the urethra of a boy from three to six will admit a No. 7 or 8 English; that of a boy from eight to ten a No. 10, 11, and even sometimes No. 14 English, but age cannot always be depended on as the measure of urethral capacity. In some children of four or five it is unsafe to pass a No. 7 lithotrite, although an instrument of this size will sometimes pass readily into the bladder of a boy of only two years of age.

The objections that have been urged against litholapaxy in male children are :

(1) The undeveloped condition of the genito-urinary organs.

(2) The small size of the bladder.

(3) The narrowness of the urethra, and its extreme sensitiveness and liability to laceration.

These objections Mr. Walsham considers chimerical. Thus :

(1) As regards the undeveloped condition of the genito-urinary organs, the small size of the prostate is altogether in favor of the operation, since, as we all know, an enlargement of that organ is one of the chief difficulties attending lithotrity in old men.

(2) The bladder is, no doubt, smaller in young children than in adults. But many lithotritists prefer to work with only two or three ounces of water in the bladder; and, in boys of only three or four years old, the bladder is quite roomy enough to permit of the efficient working of a small lithotrite, and such was found to be the case with the bladder of the infant of fifteen months, operated on by Mr. Willett. Further, a child's bladder is more expansive and commonly in a healthier condition than that of an adult, and, therefore, better able to bear any over-distension than the bladder of old men. But of over-distension there need be no fear if a small-sized aspirator is used, or if care is taken to force in only a limited quantity of fluid if a full-sized aspirator is employed.

Of the third objection, the narrowness of the urethra has been already considered.

Mr. Walsham believes the alleged extreme sensibility of the urethra in children to be over-rated; since, as far as he has observed, boys, when they have once got over the timidity of having an instrument passed, bear it quite as well, if not better, than do lads about puberty and adults. Boys have sometimes felt so little that they have much preferred being sounded without chloroform.

As regards the actual performance of the operation, 